Research Article

\title{
Effect of Health Education on Adolescent Girls' Knowledge about Family Life Education
}

\author{
Bharati Suresh Batra', Hancy Collins \\ ${ }^{1}$ Ph.D. Supervisor, SRK University, Bhopal. \\ ${ }^{2}$ Ph.D. Scholar, RKDF College of Nursing, Bhopal. \\ DOI: https://doi.org/10.24321/2455.9199.201902
}

\section{I $\quad \mathbf{N} \quad \mathbf{F} \mathbf{O}$}

\author{
Corresponding Author: \\ E-mail Id: \\ hancycollins@yahoo.co.in \\ Orcid Id: \\ How to cite this article: \\ 2019; 6(1): 3-5. \\ Date of Submission: 2019-07-08 \\ Date of Acceptance: 2019-08-01
}

Hancy Collins, RKDF College of Nursing, Bhopal.

https://orcid.org/0000-0001-5420-1607

Batra BS, Collins H. Effect of Health Education on Adolescent Girls' Knowledge about Family Life Education. Int J HealthCare Edu \& Med Inform

\author{
$\begin{array}{llllllll}\mathbf{A} & \mathbf{B} & \mathbf{S} & \mathbf{T} & \mathbf{R} & \mathbf{A} & \mathbf{C} & \mathbf{T}\end{array}$
}

Health behaviors are created and life courses are mapped during adolescent period. Lack of awareness about family life leaves adolescent girls susceptible to increased risk from sexual assault, pregnancy and violence. The aim of this study was to assess the effect of health education on adolescent girls' knowledge about family life education. A total of 50 adolescents from a selected school were selected using simple random sampling technique after meeting the inclusion and exclusion criteria. The pre-test was conducted using a structured questionnaire in the language of their preference after obtaining administrative permission from the school. Health education was imparted using Power Point. Seven days later post-test was conducted using the same structured questionnaire. Data collected was analyzed by using SPSS version 11 . The pre-test knowledge score mean percentage was $47.28 \%$, post test knowledge score mean percentage was $66.8 \%$ and ' $Z$ ' value was 8.71 which is statistically significant at $p=0.05$. The result of the study demonstrated that health education on family life education is effective in improving the knowledge level of adolescent girls. This study would benefit the adolescent girls and in turn the society at large as they are the future mothers and responsible family members.

Keywords: Adolescent Girls, Knowledge, Family Life Education

\section{Introduction}

Adolescence is a time marked by significant physical, psychosocial and cognitive changes in life..$^{1}$ t is an important period where a child undergoes transformation biologically characterized as puberty, changes in physical appearance and attains reproductive capacity. ${ }^{2}$ According to WHO, adolescence is defined as the period belongs to 10-19 years of age and out of 1.2 billion adolescents globally, $85 \%$ resides in developing countries. Adolescents form $20 \%$ of the total world's population. ${ }^{3}$ The term family life, reproductive health and education on population are interconnected with each other. ${ }^{4}$ Health behaviors are formed and life courses are drawn during the second decade of life. ${ }^{5}$ Family life education is the educational effort to enrich and improve the quality of individual and family life by teaching the families and to prevent problems before they occur, and this education helps in making the family life happy. ${ }^{6}$ IEC (information, education and communication) camps and regular visits by health workers will create awareness among adolescent girls and their parents about the consequences of negative health, sex education, early marriage and large family size. The family life education also helps to face different problems which are likely to 
happen in the family. It is therefore necessary to empower adolescent girls so as to enable them to make responsible choices in all aspects of family in the future endeavors.

\section{Background}

Different settings of the study shows that adolescents are in need of family life education to built a better society as they are the backbone of a family.

An awareness regarding family life education concepts was conducted among 27 institutionalized adolescent girls residing in two destitute homes of Jammu city. Samples were selected by purposive sampling technique through interview method. The results revealed that majority of adolescent girls had knowledge about nutritious food and insisted that they should always prefer balanced diet to become healthy. In both institutions, adolescent girls responded that marriage was compulsory for every individual and right age of marriage is between 21 years to 25 years. The study revealed that respondents improved knowledge regarding various concepts of family life education and they reported that the information received from the researcher was quite valuable as this helped them in clarifying their doubts regarding different concepts in family life education. ${ }^{7}$

A qualitative research study was conducted among 50 female participants (adolescent girls and young women) in a rural area of Uttarakhand on family life education issues through the use of various communication aids. The findings concluded that if proper use of communication aid is carried out the program can be more interesting and easy to learn. The study also recommended that village workers should be trained properly so that they will be able to communicate effectively in the village on family life issues. ${ }^{8}$

A study on the knowledge and attitude of adolescents, their parents and teachers on family life education was performed from 23 randomly selected schools in Mumbai, under training research and action center. The samples selected for the study randomly was 2723 adolescents, 128 teachers and 629 parents. The findings clearly reveals that adolescents who have undergone family life education have better knowledge about physical changes during adolescence, sex and sexuality, Sexually Transmitted Diseases (STD) and sexual abuse. 68\% teachers and 71\% parents reported that imparting family life education would bring a positive behavioral outcome among adolescents. The study recommended that providing family life education is a critical component in the spectrum of services, a culturally sensitive and appropriate program should be designed and implemented for a better society. ${ }^{9}$

A survey was conducted in Jamaican primary schools for 501 students ( 273 Health and Family Life Education (HFLE), 228 Non Health and Family Life Education (Non HFLE) to evaluate the health and family life education program. The findings shows overall grade students from HFLE schools reported more positive attitude, greater knowledge and less risk behaviors than students from Non HFLE. The research study suggests that HFLE program has been largely successful in Jamaican primary schools and some HFLE schools were not implementing the program effectively. ${ }^{10}$

\section{Methodology}

In this study evaluative research approach was used and one group pre-test, post- test design was adopted. Data was collected from 50 adolescent girls through simple random sampling method. Formal permission was taken from principal of Mount Carmel Senior Secondary School, Bhopal. Pre-test knowledge of adolescent girls was assessed, simultaneously health education was imparted and subsequently post-test was done by using the same self structured questionnaire which consisted of 25 items and assessed on 5 categories i.e. poor (1-5), average (610), medium (11-15), good (16-20) excellent (21-25). Prior to collecting the information an informed consent was taken from all the participants. Once the data is collected it was planned to analyze and interpret the data by using descriptive and inferential statistics. Mean, standard deviation, " $Z$ " test was compared from the raw score obtained in pre-test and post-test from the participants.

\section{Result}

Table I.Socio demographic details of the adolescent girls

$(\mathrm{N}=50)$

\begin{tabular}{|c|c|c|c|}
\hline $\begin{array}{l}\text { S. } \\
\text { No. }\end{array}$ & Parameters & Frequency & Percentage \\
\hline \multirow[t]{4}{*}{1.} & Age in years & & \\
\hline & $13-14$ & 27 & $54 \%$ \\
\hline & $15-16$ & 21 & $42 \%$ \\
\hline & $17-18$ & 2 & $4 \%$ \\
\hline \multirow[t]{4}{*}{2.} & Type of Family & & \\
\hline & Nuclear & 35 & $70 \%$ \\
\hline & Joint & 14 & $28 \%$ \\
\hline & Extended & 1 & $2 \%$ \\
\hline \multirow[t]{3}{*}{3.} & Education & & \\
\hline & Class IX & 35 & $70 \%$ \\
\hline & CLASS XI & 15 & $30 \%$ \\
\hline \multirow[t]{5}{*}{4.} & Source of Information & & \\
\hline & Mass Media & 29 & $58 \%$ \\
\hline & Health Personnel & 8 & $16 \%$ \\
\hline & Relatives & 9 & $18 \%$ \\
\hline & Friends & 4 & $8 \%$ \\
\hline
\end{tabular}


Table 2.Knowledge of adolescent girls about family life education assess the pre-test level of knowledge score of adolescent girls regarding family life education in terms of Frequency, Percentage

\begin{tabular}{|c|c|c|c|c|}
\hline \multirow{2}{*}{$\begin{array}{c}\text { Knowledge } \\
\text { Scores }\end{array}$} & \multicolumn{4}{|c|}{ Pre-test } \\
\cline { 2 - 3 } & Frequency & Percentage & Mean & S.D. \\
\hline Poor & 2 & $4 \%$ & & \\
\hline Average & 11 & $22 \%$ & & \\
\hline Medium & 31 & $62 \%$ & \multirow{2}{*}{11.82} & 3.04 \\
\hline Good & 6 & $12 \%$ & & \\
\hline Excellent & 0 & 0 & & \\
\hline
\end{tabular}

Table 3.Assess the Post-test level of knowledge score of adolescent girls regarding family life education in term of Frequency, Percentage

\begin{tabular}{|c|c|c|c|c|}
\hline \multirow{2}{*}{$\begin{array}{c}\text { Knowledge } \\
\text { scores }\end{array}$} & \multicolumn{3}{|c|}{ Post Test } \\
\cline { 2 - 3 } & Frequency & Percentage & Mean & S.D. \\
\hline Poor & - & - & & \\
\hline Average & - & - & \multirow{2}{*}{16.7} & \multirow{2}{*}{2.6} \\
\hline Medium & 20 & $40 \%$ & \\
\hline Good & 30 & $60 \%$ & & \\
\hline Excellent & - & - & & \\
\hline
\end{tabular}

Table 4.Comparison of pre-test and Post-test level of knowledge score of adolescents regarding family life education

\begin{tabular}{|c|c|c|c|}
\hline S. No. & Test & Mean Score & 'Z' test value \\
\hline 1 & Pre-test & 11.82 & \multirow{2}{*}{8.71} \\
\hline 2 & Post-test & 16.7 & \\
\hline
\end{tabular}

The data presented in the table 4 , shows that the pretest knowledge score mean is 11.82 and post-test mean is 16.7 percentage is $47.28 \%$, post-test knowledge score mean percentage is $66.8 \%$ and ' $Z$ ' value is 8.71 which is statistically significant at $p=0.05$

\section{Discussion}

The present study was conducted among adolescent girls in order to evaluate their knowledge regarding family life education. The findings showed that post- test level knowledge of adolescent girls regarding family life education improved significantly.

\section{Conclusion}

The nursing curriculum has to focus on enabling the nursing students to develop the knowledge about family life education. Nursing personnel should be encouraged to impart health education to adolescents on family life education and encourage them to adopt a positive attitude towards healthy life style. Evidence based nursing practice must be taken into account in order to increase the awareness about family life education to adolescent girls.

\section{Acknowledgement}

The authors would like to acknowledge Sr. Shanti, Principal Mount Carmel Senior Secondary School and Dr. Yash Saraf MBBS, MD professor Department of Community Medicine, statistic guide for their assistance in completing the study.

Financial Implication: Self-Funded

\section{Conflict of Interest: None}

\section{References}

1. Agampodi SB, TC Agampodi. Adolescent's perception of reproductive health care services in Srilanka. BMC health service research 2008; 3(8): 98.

2. Manus AM, Dhar L. Study of knowledge, perception and attitude of adolescent girls towards Sexually Transmitted Infections, safer sex, sexual education. BMC women's health 2008; 8: 12.

3. Improving adolescent health and development. The $2^{\text {nd }}$ decade, WHO/FRH/ADH/92.18; 2.

4. WHO school health Department of NCD prevention and health promotion family life, reproductive health and population education - key elements of a health promoting school, Geneva Switzerland WHO. 2003; 1-15.

5. Program for appropriate tech in health highlights of 25 years of youth sexual and reproductive health programming 2003; 3-5.

6. https://en.wikipedia.org/wiki/family life education.

7. Arora S, Thakur R, Devi V. Awareness regarding family life education concepts among institutionalized adolescent girls. International journal of multidisciplinary Research and Development 2016; 3(4): 273-276.

8. Saxena R, Srivastava N, Ahuja A. Educating adolescent girls and young women on family life education issues with the use of communication aid in a village of Uttrakhand. Journal of Social Sciences 2017; 73-78. DOI: 10.1080/09718923.2009.11892753.

9. Knowledge and attitude of adolescents, their parents and teachers on family life education in schools in Mumbai. TRAC 1-24. https://books.google.co.in/books id bjcod9mg52WC.

10. Kazaara J. Impact assessment of Health and family life education in Jamaica. International Journal of Business and social Research (IJBSR) 2013; 3(1): 98-107. 